\title{
Gestão Democrática na Escola Pública Contemporânea
}

\author{
Tereza Priscila Silva Oliveira Carvalho ${ }^{1}$ : Liliany Souza Costa ${ }^{2}$; Lucimara Araújo Campos Alexandre ${ }^{3}$
}

\begin{abstract}
Resumo: O objetivo geral deste artigo é descrever como acontece a gestão democrática e suas contribuições para a melhoria do desempenho organizacional, funcional e resultados alcançados na Escola Simão Angelo. A problemática: saber como a gestão democrática está acontecendo na escola e como a descentralização, participação e transparência podem aumentando a qualidade e efetividade do ensino. A metodológica é exploratória qualitativa/ quantitativa. A técnica de coleta de dados utiliza observações, análises documentais, entrevista para os segmentos da escolar. Será realizada uma revisão bibliográfica por meio de leitura de teóricos que tratam do processo de gestão democrática da escola pública, possibilitando uma maior fundamentação do problema investigado. O interesse pela pesquisa surgiu da necessidade de conhecer como o núcleo gestor da escola pratica a gestão democrática para conquistar uma educação ideal. Os resultados demonstraram que os gestores e demais segmentos conhecem e vivenciam os princípios da gestão democrática no cotidiano escolar.
\end{abstract}

Palavras-chave: Gestão Democrática. Escola Pública. Participação. Resultados.

\section{Democratic Management at the Contemporary Public School}

\begin{abstract}
The general objective of this article is to describe how democratic management happens, its contributions to improve organizational functional performance, and the results achieved at the Simão Angelo School. The problem: to know how democratic management is happening in school and how decentralization, participation and transparency can increase the quality and effectiveness of teaching. The methodology is qualitative / quantitative exploratoration. The technique of data collection uses observations, documentary analysis, interview with the segments of the school. A bibliographic review will be carried out by reading theorists that deal with the process of democratic management of public schools, allowing for a better foundation of the problem investigated. The interest in the research arose from the need to know how the core managers of the school practices democratic management to achieve an ideal education. The results showed that managers and other segments know and live the principles of democratic management in school everyday.
\end{abstract}

Keywords: Democratic Management. Public school. Participation. Results.

\section{Introdução}

As transformações pelas quais vem passando a sociedade na atualidade requer muitas mudanças estruturais em todas as áreas, principalmente na educacional. A escola é o principal meio de transformação social, pois tem uma indispensável função que é ensinar bem e trabalhar a formação do sujeito como ser pensante, livre, honesto, responsável, consciente e crítico, isto é, cuidar do desenvolvimento pleno do indivíduo preparando-o para desenvolver

${ }^{1}$ Graduanda do Curso de Administração Pública - Universidade Federal do Vale do São Francisco (UNIVASF) Secretaria de Educação a Distância (SEAD). E-mail priscillasilvabs@ gmail.com Telefone:03188988853679

${ }^{2}$ Graduanda do Curso de Administração Pública - Universidade Federal do Vale do São Francisco (UNIVASF) Secretaria de Educação a Distância (SEAD). E-mail lilianysouzacosta@gmail.com telefone:03188988787887. ${ }^{4}$ Prof. ${ }^{a}$ Orientadora e Assistente do Colegiado de Enfermagem da UNIVASF - Petrolina-PE. E-mail lucimara.univasf@gmail.com. 
funções sociais enquanto cidadão, ou seja, instrumentalizar o cidadão para sentir-se motivado a participar da vida política e pública da sociedade com muita competência, além de saber "lidar com a diversidade e o conflito de ideias, com as influências da cultura, e com os sentimentos e emoções" (ARAÚJO, 2005, p. 7).

Para Libâneo ( 2004) a escola está incumbida de desenvolver com eficiência e eficácia sua função social e pedagógica para garantir o desenvolvimento das capacidades cognitivas, operativas, sociais e morais do educando atingindo a formação da cidadania participativa e ética.

Para Menezes-Filho (2001), “A educação é o veículo para a construção de uma sociedade igualitária, visto que a desigualdade é em grande parte resultado da péssima distribuição educacional existente, em termos pessoais e grupos de indivíduos com características similares”. Por ser tão significativa para a vida, os brasileiros sempre sonharam com a escola ideal, aquela que proporciona o saber para todos. Assim, muitos movimentos foram surgindo desde a década de 1932, em prol de uma educação para todos, busca da democratização, descentralização e autonomia da escola em todos os aspectos: técnicos, administrativos, financeiros, pedagógicos, dentre outros.

No início da década de 1980, os movimentos a favor da descentralização e da democratização da administração das escolas públicas foram iniciados e a cada dia ficando mais fortes. Surgiram várias reformas no setor educacional, além de proposições legislativas que reconheciam a importância da democratização da gestão escolar como um dos requisitos para o aprimoramento da qualidade educacional (LUCK, 2005).

O presente estudo terá como problemática: Como a institucionalização da gestão democrática está acontecendo na Escola Simão Angelo? A descentralização, participação e transparência aumentam a qualidade e efetividade do ensino na escola?

Serão comentados e citados aspectos que tornam o trabalho da escola eficaz apresentando ações desenvolvidas na gestão de resultados educacionais, gestão pedagógica, gestão participativa, gestão de pessoas e gestão de serviços e recursos. Será apresentado o rendimento escolar dos alunos nas avaliações externas e internas nos anos 2015 e 2016, além. de uma análise sobre os principais pontos que dificultam o desempenho da escola.

O interesse pela pesquisa surgiu da necessidade de conhecer como o núcleo gestor da escola, única de ensino médio na localidade, vivencia a prática da gestão democrática como 
estratégia para conquistar uma educação ideal. O presente estudo tem como objetivo geral descrever como acontece a gestão democrática na escola Simão Angelo e suas contribuições para a melhoria do desempenho organizacional, funcional e resultados alcançados. Seus objetivos específicos são: investigar se o núcleo gestor da escola está cumprindo os princípios da gestão democrática; identificar se a prática educativa está colaborando para a formação de cidadãos pensantes, livres, conscientes, críticos, autônomos e participativos e indagar sobre as ações desenvolvidas pela escola na gestão de resultados educacionais, gestão pedagógica, gestão participativa, gestão de pessoas e gestão de serviços e recursos.

A pesquisa acontecerá na Escola de Ensino Médio Simão Angelo em Penaforte Ceará. Em 2017 apresenta uma matrícula de 555 alunos no Ensino Médio Regular e Educação de Jovens e Adultos. Utiliza-se do processo de amostragem com 30 participantes escolhidos aleatoriamente envolvendo o núcleo gestor, professores, servidores, alunos e seus representantes. Será realizada uma pesquisa de campo de caráter exploratório e de natureza qualitativa e quantitativa utilizando como técnica de coleta de dados a entrevista estruturada, contendo questões abertas, previamente elaboradas, para os diferentes segmentos da comunidade escolar.

Os resultados da pesquisa vão mostrar se a escola está ou não, pautada em uma gestão democrática, havendo participação de todos os atores que fazem parte direta ou indiretamente da comunidade escolar, além de poder contribuir como experiência para a formação de gestores atuantes e esclarecidos sobre a gestão democrática.

A gestão escolar é uma forma de administrar a escola em todos os aspectos para que atenda aos anseios da sociedade e para tal é necessário articular ações de modo a atingir o objetivo fim da escola que é o desenvolvimento pleno do educando. Também implica uma administração participativa, democrática, com decisões compartilhadas onde todos são responsáveis pelos resultados alcançados uma vez que não é apenas o gestor o responsável pela escola, mas toda a comunidade escolar, principalmente quando é necessário tomar decisões. O compromisso é coletivo para que os resultados educacionais sejam cada vez mais efetivos e significativos. Gestão é mobilização de competência, energia de pessoas coletivamente organizadas, participando ativamente e com competência, promovendo a realização plena dos objetivos de sua unidade de trabalho, no caso, os objetivos educacionais (LUCK, 2006, p. 21). 
São várias gestões que integram e fundamentam o cotidiano escolar. $\mathrm{O}$ desenvolvimento de todas acontece interligado:

Gestão Pedagógica: O foco é o ensino aprendizagem e, portanto é o pilar mais importante da gestão escolar por estar voltada para a atividade fim do setor educacional que é o ensino-aprendizagem. Estabelece objetivos, propõe metas, elabora os conteúdos curriculares, avalia o desempenho de todos que compõem a escola. "Um trabalho com ação participativa em que todos os integrantes têm um alvo comum é indubitavelmente satisfatório e positivo" (SILVA, 2005, p. 25).

Gestão Administrativa: Voltada para os recursos físicos, financeiros e materiais da instituição, de modo que sejam bem utilizados para atingir as metas que é um ensino de qualidade. Cuida da parte física e institucional, portanto o gestor precisa ter visão de conjunto e de futuro relacionada ao trabalho da escola e o seu papel na comunidade; conhecimento de política e da legislação educacional; saber planejar e perceber a importância do seu papel na orientação do trabalho conjunto; habilidades diversas como a de manejo e controle do orçamento, organização do trabalho, acompanhamento e monitoramento de programas, projetos, ações, avaliação diagnóstica, formativa e somativa, tomar decisões eficazmente, resolver problemas criativamente e saber empregar grande variedade de técnicas (LÜCK 2005, p. 84).

Gestão de Recursos Humanos: Manter um relacionamento satisfatório com alunos, funcionários, educadores e com a comunidade de pais e responsáveis. É uma área que requer muita atenção por parte do gestor.

Gestão de Resultados Educacionais: É voltada para os resultados alcançados pela escola e devem ser bem monitorados e analisados.

Gestão participativa: Enfatiza que para conquistar o sucesso escolar é necessário que o gestor conheça competências, habilidades e a experiências dos recursos humanos que trabalham na escola e incentivar a participação de todos delegando responsabilidades e poder para os representantes da comunidade escolar. "A participação é o principal meio de se assegurar a gestão democrática da escola, possibilitando o envolvimento de profissionais e usuários no processo de tomada de decisões e no funcionamento da organização escolar" (LIBÂNEO, 2004, p.79).

$\mathrm{Na}$ atualidade é impossível imaginar uma escola sem autonomia e com decisões centradas no diretor. Em um mundo globalizado a escola precisa de uma gestão democrática, onde acontece a real participação de todos os atores da comunidade escolar nas etapas da 
gestão: planejamento, implementação e avaliação. Os caminhos, buscados para democratização do ensino público, vêm sendo apontados com bastante ênfase, nas últimas décadas, principalmente por educadores e ou sujeitos envolvidos direta ou indiretamente com o trabalho pedagógico desenvolvido na escola (SCHNECKENBERG, 2005, p. 15).

Sendo a escola concebida como um instrumento para transformação social, a preocupação em proporcionar uma gestão democrática na escola surgiu com a Constituição Federal de 1988 quando consolidou a gestão democrática nos sistemas públicos de ensino. "A gestão democrática valoriza a participação da comunidade escolar na tomada de decisão, concebe a docência como trabalho interativo, aposta na construção coletiva de objetivos e das práticas escolares, no diálogo e na busca do consenso" (LIBÂNEO, 2011, p. 344).

O Art. 206 da Constituição Federal de 1988 estabelece os princípios sobre os quais o ensino deve ser ministrado. Dentre eles, destaca-se a gestão democrática do ensino público.. Garante uma gestão participativa no ensino público, assegurando o caráter democrático da educação de forma "que as instituições públicas possam criar uma cultura político-educativa de exercício do princípio e da prática democrática, no seu cotidiano" (BRASIL, 2006).

Conforme o Art. 205 da Constituição Federal do Brasil de 1988, a Educação é um direito de todos e dever do Estado e da família e será promovida e incentivada com a colaboração da sociedade, visando ao pleno desenvolvimento da pessoa, seu preparo para o exercício da cidadania e sua qualificação para o trabalho. Para que esse direito seja plenamente cumprido e a escola seja um meio de ascensão social e tenha condição plena de cumprir suas metas e missão é necessário que tenha uma gestão democrática, seja autônoma e participativa (BRASIL, 2006).

A Lei de Diretrizes e Bases da Educação (LDB) n 9.394/96, fixou as incumbências dos estabelecimentos de ensino, determinando em seu Art.14 que os sistemas de ensino definirão as normas da gestão democrática do ensino público na educação básica, de acordo com as suas peculiaridades e conforme os seguintes princípios: participação dos profissionais da educação na elaboração do projeto pedagógico da escola e participação das comunidades escolar e local em conselhos escolares ou equivalentes (Art. 14, incisos I e II).

Essa garantia legal só é possível em uma gestão democrática e participativa. Conforme o Art. 15 da Lei de Diretrizes e Bases da Educação (LDB) $n^{\circ}$ 9.394/96, os sistemas de ensino assegurarão às unidades escolares públicas de educação básica que os integram, progressivos 
graus de autonomia pedagógica e administrativa e de gestão financeira observadas as normas gerais de direito financeiro público (BRASIL, 1996).

Conforme Araújo (2000) existem quatro elementos que são fundamentais para que uma gestão seja democrática: a participação onde gestor não atua sozinho, o trabalho é coletivo; o pluralismo que é o respeito às ideias e opiniões de todos da comunidade escolar; a autonomia em todos os aspectos, principalmente pedagógica e financeira; transparência que é quem afirma a dimensão política da escola. Sua existência pressupõe a construção de um espaço público vigoroso e aberto às diversidades de opiniões.

As constantes transformações sociais, cientificas e tecnológicas exigem uma nova escola e, em decorrência, um novo diretor, uma gestão democrática. A aprendizagem do educando depende muito da capacidade administrativa do núcleo gestor, pois além de aprender com as orientações recebidas na sala de aula, também aprende na escola como um todo (ARAÚJO, 2009).

O Plano Nacional de Educação (PNE), aprovado pela Lei $\mathrm{n}^{\circ}$ 10.172, de 09 de 2001, em seu subitem 10.2 diz que: “A educação escolar não se reduz à sala de aula e se viabiliza pela ação articulada entre todos os agentes educativos".

Sobre a gestão escolar, Libâneo (2005) afirma que o diretor deve ser um líder pedagógico apoiando as prioridades; avaliando a equipe e se auto avaliando; participando na elaboração de programas de ensino e de programas de desenvolvimento e capacitação de funcionários; incentivando e estimulando o trabalho da equipe e a reflexão sobre sua prática pedagógica; cooperando na solução de problemas pedagógicos; enfatizando os resultados alcançados pelos alunos.

De acordo com Borges (2008, p. 83), dirigir uma escola implica colocar em ação os elementos do processo organizacional (planejamento, organização, avaliação) de forma integrada e articulada. Isso significa que o diretor precisa ser possuidor de todas as características de um líder, principalmente saber tomar decisões, saber ouvir e liderar o grupo. O diretor de uma escola é um líder e como tal deve valorizar o trabalho coletivo, seu trabalho ser pautado na participação ativa de todos os segmentos da comunidade escolar, ter postura positivo, incentivar a equipe a produzir mais e melhor, ser perseverante, otimista, ter autonomia, saber enfrentar os desafios com determinação e competência. "O gestor escolar tem de se conscientizar de que ele, sozinho, não pode administrar todos os problemas da 
escola. O caminho é a descentralização, isto é, o compartilhamento de responsabilidades com alunos, pais, professores e funcionários” (PARO, 2008, p.130).

São muitas as atribuições de um gestor escolar: supervisionar atividades administrativas e pedagógicas; promover a integração entre escola e comunidade; conhecer a legislação educacional; buscar meios que favoreçam sua equipe, dentre outras. Assim, precisa está preparado para o exercício dessas atribuições, participando de formação continuada, estudando constantemente na busca do aprimoramento e amadurecimento criando uma bagagem de experiências enriquecidas que podem ser compartilhadas com a comunidade escolar favorecendo o desenvolvimento profissional de toda a equipe para que a escola possa cumprir o seu papel social (LIBÂNEO, 2004, p. 269).

\section{Metodologia da Pesquisa}

A pesquisa que origina o presente TCC tem como local de estudo a Escola de Ensino Médio Simão Angelo, localizada no município de Penaforte, Estado do Ceará, pertencente à rede pública estadual, funcionando apenas com o Ensino Médio nas modalidades regular ( $\left(1^{\circ}\right.$, $2^{\circ}$ e $3^{\circ}$ séries) e Educação de Jovens e Adultos (Curso presencial com avaliação no processo). Em 2017 apresenta uma matricula de 460 alunos na modalidade regular e 95 na Educação de Jovens e Adultos.

Para o desenvolvimento da pesquisa, inicialmente será feita uma revisão bibliográfica por meio de leitura de teóricos que tratam do processo de gestão democrática da escola pública, possibilitando uma maior fundamentação do problema investigado. Logo após acontecerá a pesquisa de campo de caráter exploratório e de natureza qualitativa e quantitativa utilizando como técnica de coleta de dados a entrevista estruturada, contendo questões abertas, previamente elaboradas para os diferentes segmentos da comunidade escolar. Também serão utilizadas observações e análise de documentos.

Será utilizado o processo de amostragem com 30 participantes escolhidos aleatoriamente: 01 diretor geral, 02 coordenadores pedagógicos, 01coordenador financeiro, 01 secretária da escola, 07 professores, 01 merendeira, 02 serventes, 02 vigias, 02 administrativos, 04 pais de alunos e 07 alunos. $\mathrm{O}$ total de 30 participantes representa todos os 
segmentos da escola cujo ponto de vista ficará registrado através do questionário respondido. Após esse momento será realizada uma nova etapa da pesquisa através de uma entrevista informal onde serão ouvidos $10 \%$ dos alunos de cada série, $30 \%$ dos professores e $30 \%$ dos demais servidores da escola, que não participaram da entrevista estruturada, sobre a importância da gestão democrática na escola pública contemporânea onde será feito um paralelo com a escola pesquisada.

Concluída a pesquisa será feita a analise dos dados através da seleção que é um exame minucioso a fim de detectar falhas ou erros e apresentados os resultados. Espera-se que as informações apresentadas atendam as expectativas do leitor, ampliando suas experiências em gestão democrática na escola contemporânea.

\section{Resultados}

Os resultados estão apresentados de duas formas: os quantitativos através de tabelas e/ou quadros e os qualitativos através de citações descritivas dos entrevistados respeitando integralmente as opiniões de cada participante.

\section{A realidade da escola Simão Angelo}

A Escola de Ensino Médio Simão Angelo localiza-se na cidade de Penaforte- Ceará. Pertencente à rede de Ensino Oficial, mantida pelo Estado e subordinada técnico e administrativamente aos órgãos da Secretaria da Educação. Em 2017 ministra apenas o Ensino Médio Regulas nos turnos manhã, tarde e noite e Ensino Médio Educação de Jovens e Adultos apenas no noturno. Apresenta uma matricula de 460 alunos na modalidade regular e 95 na Educação de Jovens e Adultos.

Uma parcela considerável dos alunos é baixa renda e precisam trabalhar para ajudar no orçamento familiar, o que interfere negativamente no desempenho acadêmico por dispor de pouco tempo para estudo domiciliar, adicionado ao cansaço que impede uma participação satisfatória em sala de aula. Aproximadamente 30\% dos alunos residem na zona rural e 
dependem do transporte escolar. A direção da Escola é constituída por um Diretor Geral; dois Coordenadores Pedagógicos; um secretário; um assessor financeiro.

\section{O papel de cada segmento da escola}

DIRETOR GERAL: Trabalhado coletivamente, ouvindo a opinião da comunidade escolar antes de adotar qualquer decisão. Incentivo todos a participarem, observo habilidades e competências de cada um. Meu foco é o desenvolvimento da escola, a preparação do educando para a vida e manter um ambiente agradável para todos.

COORDENADOR (A) 1: O que mais caracteriza a escola é o espírito com que os profissionais trabalham respeitando à legislação, a liberdade que professores e alunos têm para aprender a aprender e aprender a ensinar, respeitando o pluralismo de ideias e pensamentos.

COORDENADOR(A) 2: Cuido principalmente da parte pedagógica da escola. Busco atender aos anseios do educando, oferecendo - lhes uma ação pedagógica eficiente. Bimestralmente, com o apoio do diretor, reúno os professores para capacitação por área do conhecimento, onde os professores de cada área fazem revezamento na capacitação, ou seja, a cada encontro um professor é responsável pela capacitação em sua área e o núcleo gestor é responsável pela confecção do material, acompanhamento e avaliação.

PROFESSOR(A) 1: Participamos ativamente da construção e execução do Projeto Político Pedagógico da escola, pois ele determina o caminho que devemos seguir. Preocupamo-nos em adotar um processo de ensino-aprendizagem contextualizado e interdisciplinar para estimular a curiosidade, a pesquisa e a descoberta do saber.

COORDENADOR FINANCEIRO: Colaboro com o planejamento das finanças da escola; zelo por uma aplicabilidade coerente com as prioridades. Juntamente com o núcleo gestor fazemos o controle financeiro e a prestação de contas expondo os resultados para a comunidade; solicito a participação de todos os segmentos da escola no planejamento da aplicação dos recursos. 
PROFESSOR (A) 2: Participamos da articulação e construção do projeto da escola, todos somos responsáveis pelo sucesso ou fracasso escolar. Convivemos diariamente com o aluno(a), somos conhecedores das suas expectativas e necessidades. Para que o nosso trabalho traga o sucesso desejado atuamos em sintonia com o Projeto Político Pedagógico e o regimento escola. Buscamos desenvolver o nível intelectual, físico, emocional, social, cultural do aluno; respeitar as diferenças, reconhecendo as possibilidades de cada um; buscamos ajuda da família do aluno quando há necessidade; avaliamos continuamente os processos de ensinoaprendizagem; estamos abertos ao diálogo.

AUXILIAR DE SERVIÇOS GERAIS 1: Cuido da cozinha para que esteja sempre limpa e organizada conforme a legislação sanitária em vigor; preparo e sirvo a merenda aos alunos conforme o cardápio do dia; mantenho o diretor informado sobre o estoque da merenda escolar; cumpro todas as atribuições de acordo com o regimento escolar.

AUXILIAR DE SERVIÇOS GERAIS 2: Zelo pela segurança de todos da escola; cuido do ambiente escolar para que o patrimonio esteja em perfeita ordem; coordeno e oriento a movimentação dos alunos, desde o início até o término dos períodos de atividades escolares.

AUXILIAR DE SERVIÇOS GERAIS 3: Mantenho a escola limpa e organizada; transfiro mobiliario e equipamentos de um local para outro; uso racionalmente o material de limpeza; zelopela conservação do patrimônio escolar;ajudo na locomoção de alunos com necessidades especiais; coleto o lixo de todos os ambientes da escola.

AUXILIAR ADMINISTRATIVO 1: Colaboro com todos os segmentos da escola e auxilio o secretario escolar nos trabalhos burocráticos.

ALUNO 1: A escola existe para o aluno, assim sendo nosso dever é cuidar bem da escola, respeitar toda a comunidade escolar e estudar muito para que tenha um desempenho satisfatório. 
PAI DE ALUNO (1): Acompanho diariamente o desempenho do meu filho, mantenho, com ele, um diálogo constante e esclarecedor para que cumpra todos os seus deveres e valorize a escola, local que vai prepara-lo para a vida. Sou convidado a participar de vários momentos significativos da escola e compareço com muito prazer, afinal está colaborando muito com o sucesso do meu filho.

SECRETÁRIO DA ESCOLA: Sou responsável por registros e documentos escolares; cuido dos processos de matrícula e transferência de estudantes, organização de turmas; registros do histórico escolar dos estudantes; documentos oficiais; analiso os documentos dos alunos e averiguo se há irregularidades. Participo da elaboração do regimento escolar e faço consultas sempre que for necessário, pois minha função requer muito conhecimento desse documento de referência para o funcionamento da escola.

\section{Entendimento sobre gestão escolar democrática e conceito dado a escola}

Os vários segmentos da escola foram unanimes nas respostas:

DIRETOR GERAL: Gestão democrática é a que acontece na Escola Simão Angelo. Aqui não existe o ditador de regras e os subordinados, mas uma equipe unida, trabalho coletivo, transparente, responsável. Meu conceito para a escola é muito bom.

COORDENADOR(A) 1: Na escola existe um líder, mas não é autoritário e sim, tem autonomia e sabe realizar um trabalho compartilhado.

PROFESSOR(A) 3: Todos da comunidade escolar e civil são convidados a participar de modo que o clima é agradável e todos se sentem valorizados. Os resultados conquistados não é mérito do líder, mas de todos da escola. Essa escola é ótima.

AUXILIAR DE SERVIÇOS GERAIS 4: A gestão democrática é aquele onde todos trabalham unidos para o bem da escola. Aqui é assim, o empenho é de todos e por isso a escola é ótima. 
Id on Line Revista Multidisciplinar e de Psicoloqia

Id on Line Multidisciplinary and Psycology Journal

AUXILIAR ADMINISTRATIVO 2: Esse tipo de gestão é a que acontece na Simão Angelo. Trabalhamos coletivamente, colaboramos com todas as ações da escola. Há muito respeito, entendimento, transparência e valorização dos recursos humanos. Minha nota é 10.

SECRETÁRIO ESCOLAR: È aquela gestão onde há participação de todos os segmentos da escola. As competências e habilidades de cada um são valorizadas. Vivemos aqui esse tipo de gestão. Nossa escola é excelente.

ALUNO 2: Quando cheguei aqui, no ensino médio, não gostava de estudar. Era um aluno bastante indisciplinado ondo o ensine sem objetivos. Na Simão Angelo fui convidado a participar de todos os acontecimentos da escola e comecei a me sentir valorizado. Hoje, terminando o ensino médio e já sei que caminho seguir, tenho objetivos a perseguir. Meu conceito para a Simão Angelo é excelente.

PAI DE ALUNO 2: Pelo que entendo e velo falar de democracia é quando todo mundo participa. Antigamente nenhum pai participava da escola dos filhos, só quando era pro diretor falar mal dos filhos da gente. Hoje é diferente, venho sempre na Simão Angelo participar de tudo, dar minha opinião, isso é muito bom, gosto demais desse sistema. Essa escola é boa demais.

\section{A gestão democrática e a participação da comunidade escolar}

Neste quesito foi feita uma síntese das respostas dos professores sobre a gestão democrática e a participação da comunidade escolar:

GRUPO DE PROFESSORES: A escola Simão Angelo vivencia a gestão democrática, pois dispõe de Conselho de Classe, Conselho Escolar, Congregação de Professores, Grêmio Estudantil colaborando com êxito no desempenho do trabalho escolar. A comunidade escolar participa ativamente de todas as atividades da escola colaborando com o seu desempenho. 
GRUPO DE ALUNOS: Participamos de todas as decisões da escola dando sugestões, discutindo resultados, elaborando e vivenciando diversos projetos, colaborando com a gestão para que a escola apresente resultados satisfatórios..

\section{Qualidades do atual gestor da escola}

Através dos depoimentos dos vários segmentos da escola, a atual gestão age de forma transparente; sabe trabalhar em equipe; dialogar com os segmentos internos e externos buscando uma maior interação; é firme nas decisões; valoriza e incentiva a equipe; compartilha os resultados e afirma ser conquista de todos; procura capacitar a equipe de trabalho; age com determinação, competência e habilidade; é conhecedor da legislação que regulamenta o ensino; tem conhecimento pedagógico, administrativo e financeiro; é uma pessoa ética, compreensiva e cumpridora dos seus deveres; conhece a escola que atua e todos os segmentos da escola; dar bons exemplos e cumpre na íntegra os seus deveres, dentre outras.

\section{Órgãos colegiados existentes na escola}

DIRETOR GERAL: Valorizamos o trabalho em equipe, portanto trabalhamos em parceria com os organismos colegiados: Grêmio Estudantil, Conselho Escolar, Congregação de Professores e Associação de Pais, Mestres e Funcionários.

$A L U N O(A)$ 3: Sou do Grêmio Estudantil e me sinto muito valorizado na escola uma vez que sou convidado a participar no seu dia a dia e minhas opiniões são valorizadas.

ALUNO(A) 4: Faço parte do Conselho escolar e valorizo muito o que a escola faz para melhorar nosso desempenho no conselho. Participamos de formação continuada através de reuniões, grupo de estudos, leituras e outros. 
PROFESSOR(A) 1: Sou da Congregação de Professores e nosso trabalho é muito importante para o desenvolvimento da escola. Quinzenalmente nos reunimos para debater e encontrar soluções para problemas pertinentes à rotina escola, principalmente no tocante ao desempenho do aluno e a participação dos seus representantes nos encontros de rotina.

MÃE 2: Faço parte da Associação de Pais, Mestres e Funcionários e fazemos reuniões para debater assuntos relacionados aos nossos filhos a aos servidores da escola. São momentos bastante significativos, pois neles já encontramos soluções para muitos problemas.

$\operatorname{PROFESSOR(A)~2:~faço~parte~do~Conselho~Escola~e~posso~afirmar~que~ele~tem~muita~}$ autonomia na escola. O conselho funciona, trabalha muito tanto na elaboração do Projeto Politico Pedagógico quanto na fiscalização da sua execução.

\section{Ações desenvolvidas pela escola concretizando a gestão democrática}

\section{Gestão de resultados educacionais}

DIRETOR GERAL: Me preocupo com desenvolvimento integral do aluno, formação de valores, preparação para uma vida saudável e capacidade para atuar satisfatoriamente no mercado de trabalho. Assim, monitoramos cotidianamente os resultados alcançados pelos alunos para adotarmos medidas corretivas quando não são satisfatórios e tentamos preservar o que deu certo.

PROFESSOR (A) 4: Para que a comunidade escolar tenha acesso aos resultados, fazemos a exposição no painel Gestão à Vista, fazemos reuniões periódicas com os organismos colegiados, pais e mestres; avaliação diagnóstica do desempenho escolar.

ALUNO (A) 5: Os alunos que apresentam maior desempenho nas avaliações internas recebem medalhas de honra ao mérito, os nomes são divulgados em faixas e cartazes. 
Os alunos aprovados em concursos e vestibulares são homenageados pela escola recebendo cartões com mensagem de parabéns e todos ficam bem felizes, pois é muito gratificante.

\section{Gestão pedagógica}

COORDENADOR(A)1: Aqui os vários segmentos e órgãos colegiados atuam na execução dos projetos. A escola tem um currículo sempre atualizado; promove a Semana Pedagógica para estudos e reflexões do processo ensino-aprendizagem mantendo a avaliação diagnóstica constatando avanços e dificuldades, bem como possíveis soluções para o funcionamento satisfatório da escola.

\section{Gestão participativa}

COORDENADOR(A) 2: A escola constrói sua autonomia através de parcerias com os organismos colegiados e com outros setores sociais realizando um trabalho conjunto para o alcance dos seus objetivos.

\section{Gestão de serviços e recursos}

DIRETOR GERAL: A escola está aberta à comunidade penafortense diariamente, inclusive nos finais de semana, feriados e férias. A biblioteca e salas de multimeios estão entre os espaços disponíveis para a comunidade.

COORDENADOR DE FINANÇAS: Quando a escola é informada sobre a entrada dos recursos eu e os lideres de sala informamos a todos os alunos e nas reuniões bimestrais aos pais e anoto as opiniões sobre a aplicação do recurso. O planejamento para a aplicação dos recursos oriundos da SEDUC, passa pela aprovação do Conselho Escolar e todos os segmentos fiscalizam a aplicação. A prestação de contas é feita para a comunidade escolar consolidando uma gestão transparente e compartilhada. 
$\operatorname{ALUNO}(A)$ 6: Sou do Grêmio Estudantil e em conjunto com alunos do Conselho Escolar incentivamos todos os segmentos a buscarem formas alternativas de adquirir recursos para desenvolver projetos pedagógicos e melhorar as condições físicas e materiais da escola.

AUXILIAR DE SERVIÇOS GERAIS 5: Nossa escola é bem cuidada, limpa, organizada e bem preservada porque trabalhamos com prazer e satisfação.

$A L U N O(A)$ 7: Sou do Conselho Escolar e participo da elaboração de planos de ação, execução, acompanhamento e avaliação da aplicação dos recursos financeiros consoante as necessidades da comunidade escolar.

MÃE DE ALUNO 1: Faço parte do Conselho Escolar e um ponto que admiro muito na gestão é a transparência. Somos informados sobre o valor dos recursos recebidos e sua aplicação para que a comunidade acompanhe e avalie sua excursão..

\section{Gestão de pessoas:}

PROFESSOR(A) 5: A Escola Simão Ângelo realiza um trabalho coletivo articulando os segmentos da comunidade escolar. É estabelecida uma unidade de atuação dos diversos segmentos para estudo e análise das Diretrizes e Regimento Interno para que cada um conheça seus direitos e possa atuar satisfatoriamente. Há comprometimento e compartilhamento de responsabilidades, facilitando a participação de todos os segmentos estimulando-os a tomarem para si a responsabilidade de fazer o que for necessário para o bom desempenho da escola.

PROFESSOR(A) 6: A comunidade escolar é responsável pelos resultados obtidos e tem seus esforços e avanços reconhecidos. Existe uma preocupação em estimular, motivar e incentivar as pessoas a realizarem um trabalho eficaz 
Id on Line Revista Multidisciplinar e de Psicoloqia

Id on Line Multidisciplinary and Psycology Journal

PROFESSOR(A) 7: Professores e funcionários são qualificados através de sessões de estudos a cada bimestre, emissões de vídeos relacionados ao fazer pedagógico, reflexões e questionamentos baseados no cotidiano escolar. Todos que trabalham na escola são avaliados periodicamente através de um teste diagnóstico cujo resultado é tomado como base para ações futuras.

Os indicadores de desempenho da escola nos anos 2015 e 2016

Quadro 1: Resultado do ENEM 2015

\begin{tabular}{|c|c|c|c|c|c|c|}
\hline $\begin{array}{c}\text { Alunos que } \\
\text { participaram }\end{array}$ & $\begin{array}{c}\text { Média global } \\
\text { Escola }\end{array}$ & \multicolumn{4}{|c|}{ Média da escola por área do conhecimento } \\
\cline { 3 - 6 } & & $\begin{array}{c}\text { Ciências } \\
\text { Humanas }\end{array}$ & Matemática & $\begin{array}{c}\text { Ciências da } \\
\text { Natureza }\end{array}$ & $\begin{array}{c}\text { Linguagens } \\
\text { e } \\
\text { Códigos }\end{array}$ & Redação \\
\hline $\mathbf{9 6}$ & 461,4 & $520 \mathrm{pts}$ & $446 \mathrm{pts}$ & $427 \mathrm{pts}$ & $455 \mathrm{pts}$ & $459 \mathrm{pts}$ \\
\hline
\end{tabular}

Fonte: QEdu.org.br. Microdados do Enem/Inep (2015)

A escola não tinha dados do ENEM 2016 e a página do Inep está indisponível.

Os Resultados apresentados são referentes aos anos 2015 e 2016. Nesse período o sistema utilizou o processo de amostragem. Em 2015 participou apenas a $1^{\text {a }}$ serie do ensino médio e em 2016 apenas a $3^{\mathrm{a}}$ serie.

Quadro 2: Proficiência da escola no SPAECE 2015

\begin{tabular}{|lllll|}
\hline \multirow{2}{*}{ Instâncias } & Proficiência da $\mathbf{1}^{\mathrm{a}}$ Série do Ensino Médio & 2015 \\
& Matemática & $\begin{array}{l}\mathrm{N}^{\mathrm{o}} \text { de alunos } \\
\text { participantes }\end{array}$ & Português & $\begin{array}{l}\mathrm{N}^{\mathrm{o}} \text { de alunos } \\
\text { participantes }\end{array}$ \\
\hline Estado & 255,7 & 107932 & 253,4 & 107940 \\
\hline CREDE 20 & 250,6 & 2671 & 244,2 & 2672 \\
\hline Escola & 245,2 & 95 & 244,1 & 95 \\
\hline
\end{tabular}

Fonte: Secretaria da Educação do Ceará

Quadro 3: Proficiência da escola no SPAECE 2016

\begin{tabular}{|lllll|}
\hline Instâncias & Proficiência da $3^{\mathrm{a}}$ Série do Ensino Médio 2015 \\
& Matemática & $\begin{array}{l}\mathrm{N}^{\mathrm{o}} \text { de alunos } \\
\text { participantes }\end{array}$ & Português & $\begin{array}{l}\mathrm{N}^{\mathrm{o}} \text { de alunos } \\
\text { participantes }\end{array}$ \\
\hline Estado & 265,4 & 80112 & 265,9 & 80114 \\
\hline CREDE 20 & 261,8 & 2531 & 247,2 & 2588 \\
\hline Escola & 264,6 & 130 & 273,2 & 130 \\
\hline
\end{tabular}

Fonte: Secretaria da Educação do Ceará 
Tabela 1: Resultado acadêmico/rendimento final- 2015

\begin{tabular}{|c|c|c|c|c|c|c|c|c|}
\hline \multirow[t]{2}{*}{ Séries } & \multirow[t]{2}{*}{$\begin{array}{l}\text { Matricula } \\
\text { inicial }\end{array}$} & \multirow[t]{2}{*}{ Transferidos } & \multicolumn{2}{|c|}{ Aprovados } & \multicolumn{2}{|c|}{ Reprovados } & \multicolumn{2}{|c|}{$\begin{array}{c}\text { Deixou de } \\
\text { frequentar }\end{array}$} \\
\hline & & & $\mathrm{ABS}$ & $\%$ & $\overline{\mathrm{ABS}}$ & $\%$ & $\mathrm{ABS}$ & $\%$ \\
\hline $9^{\circ}$ Ano & 36 & 0 & 36 & 100 & 0 & 0 & 0 & 0 \\
\hline $\begin{array}{c}1^{\circ} \text { Ano Ensino } \\
\text { Médio }\end{array}$ & 151 & 01 & 106 & 70,2 & 16 & 10,6 & 28 & 19,4 \\
\hline $\begin{array}{c}2^{\circ} \text { Ano Ensino } \\
\text { Médio }\end{array}$ & 178 & 0 & 144 & 80,9 & 23 & 12,9 & 11 & 6,2 \\
\hline $\begin{array}{c}3^{\circ} \text { Ano Ensino } \\
\text { Médio }\end{array}$ & 153 & 03 & 136 & 90,7 & 09 & 6,0 & 06 & 4,0 \\
\hline EJA Médio & 105 & 0 & 47 & 44,8 & 17 & 16,2 & 41 & 39,0 \\
\hline Total & 623 & 04 & 469 & - & 65 & - & 86 & - \\
\hline
\end{tabular}

Fonte: Secretaria da Escola Simão Angelo (2017)

Tabela 2: Resultado acadêmico/rendimento final- 2016

\begin{tabular}{|c|c|c|c|c|c|c|c|c|c|}
\hline \multirow[t]{2}{*}{ Séries } & \multirow[t]{2}{*}{$\begin{array}{l}\text { Matricul } \\
\text { a inicial }\end{array}$} & \multirow[t]{2}{*}{ Admitidos } & \multirow[t]{2}{*}{ Transferidos } & \multicolumn{2}{|c|}{ Aprovados } & \multicolumn{2}{|c|}{ Reprovados } & \multicolumn{2}{|c|}{$\begin{array}{c}\text { Deixou de } \\
\text { frequentar }\end{array}$} \\
\hline & & & & $\overline{\mathrm{ABS}}$ & $\%$ & $\overline{A B S}$ & $\%$ & $\mathrm{ABS}$ & $\%$ \\
\hline $\begin{array}{c}1^{\circ} \text { Ano Ensino } \\
\text { Médio }\end{array}$ & 186 & 21 & 10 & 143 & 72,6 & 11 & 5,6 & 43 & 21,8 \\
\hline $\begin{array}{l}2^{\circ} \text { Ano Ensino } \\
\text { Médio }\end{array}$ & 129 & 10 & 02 & 97 & 70,8 & 09 & 6,6 & 31 & 22,6 \\
\hline $\begin{array}{c}3^{\circ} \text { Ano Ensino } \\
\text { Médio }\end{array}$ & 157 & 6 & 02 & 137 & 85,1 & 03 & 1,9 & 21 & 13,0 \\
\hline EJA Médio & 96 & 20 & 01 & 57 & 49,6 & 05 & 4,3 & 53 & 46,1 \\
\hline Total & 568 & 57 & 15 & 434 & - & 28 & - & 148 & - \\
\hline
\end{tabular}

Fonte: Fonte: Secretaria da Escola Simão Angelo (2017)

\section{Discussão}

É possível perceber nos depoimentos de todos os segmentos da escola que cada um tem função bem definida, mas não trabalham isoladamente, e sim, no coletivo. Todos participam ativamente das ações e são responsáveis pelo desempenho escolar. O diretor geral é o líder do grupo, tem autonomia, age com transparência e muita responsabilidade e tem consciência que é impossível alcançar os objetivos e metas sem a participação da comunidade escolar na elaboração e execução dos projetos da escola. 
Os sujeitos da pesquisa demonstraram, com segurança, que sabem o que é uma gestão democrática, citando exemplos da Escola Simão Angelo para confirmar: equipe unida, trabalho coletivo, compartilhamento de opiniões, atitudes e ações transparentes, responsabilidade, relacionamento embasado no respeito ao outro e valorização dos recursos humanos. É evidente a participação da comunidade escolar. Todos os segmentos são valorizados e tem o trabalho reconhecido pelos gestores.

O diretor demonstra em suas ações e através do desempenho da escola que é favorável ao diálogo, conhece competências e habilidades da equipe, valoriza a colaboração de todos, tem autonomia e decisão, age sempre consoante a legislação do ensino.

Observa-se que as gestões de resultados educacionais, pedagógica, participativa, serviços e recursos, gestão de pessoas concretizam a gestão democrática na escola. Os resultados apresentados pela escola ainda não são tão satisfatórios, pois as taxas de reprovação e abandono deveriam ser menores vistos o trabalho desenvolvido pela escola, porém alguns fatores dificultam o alcance de resultados mais satisfatórios e dentre os fatores negativos destacam-se o pouco tempo para estudo domiciliar por parte dos alunos que trabalham para colaborar como orçamento familiar, o deslocamento do aluno da zona rural para a urbana que demanda tempo e cansaço, uma parcela de representante de alunos que pouco frequentam a escola com a alegativa de não dispor de tempo.

\section{Conclusão}

Estudar é um direito de todos, e a escola é o caminho para uma vida melhor uma vez que se cumprir seu papel com eficiência e eficácia colabora para a formação de cidadãos pensantes, livres, conscientes, críticos, autônomos, participativos e preparados para ingressar no mercado de trabalho. Mas, é necessário que mudanças estruturais e políticas aconteçam para eliminar de forma radical o centralismo e autoritarismo que sempre impediram a participação de todos os seus segmentos, de ter autonomia, de realizar uma proposta educacional de acordo com as necessidades sociais existentes no contexto onde se encontra inserida. Para cumprir, plenamente, a sua missão institucional e atender os anseios da 
sociedade brasileira, tão ferida nos seus direitos igualitários, desde o início de sua formação, a escola precisa de uma gestão democrática (LÜCK, 2009).

Fazendo uma analise da escola pesquisada, dos depoimentos dos seus diversos segmentos, conclui-se que é uma escola de gestão democrática, gestão que conforme a Constituição federal do Brasil e a LDB é elemento obrigatório nas escolas.

Baseado na pesquisa bibliográfica, análise de documentos da escola e nas respostas dadas pelos seus sujeitos a gestão democrática está efetivada na escola pesquisada, uma vez que todos os envolvidos, diretor, coordenadores, professores, funcionários, organismos colegiados e pais de alunos são conhecedores de seus papeis para com a escola e desenvolvem um trabalho conjunto e muito responsável em prol do desempenho escolar.

\section{Referências}

ARAUJO, ULISSES F. Escola, Democracia e a Construção de Personalidades Morais. Campinas, 2005. Disponível em:

<http://www.uspl este.usp.br/uliarau/textos/artusp.pdf>. Acesso em: 10 jun. 2017.

ARAÚJO, MARIA CRISTINA MUNHOZ. Gestão Escolar. IESDE Brasil, 2009.

BORGES, HELOISA DA SILVA. Organização do Trabalho Pedagógico e Gestão Escolar. Manaus: Edições UEA Ed. Valer, 2008.

BRASIL, Constituição (1988). Constituição da República Federativa do Brasil. São Paulo: Saraiva, 2006.

Presidência da República. Lei de Diretrizes e Bases da Educação Nacional - Lei $\mathbf{n}^{0}$ 9.394, de 20 de dezembro de 1996. Disponível em:

<http://portal.mec.gov.br/arquivos/pdf/ldb.pdf>. Acessado em: 10 jul. 2017.

Lei n. 10.172, de 9 de janeiro de 2001. Aprova o Plano Nacional de Educação e dá outras providências. Diário Oficial [da] República Federativa do Brasil. Brasília, DF, 10/1/2001, p.1. Disponível em <http://www.diariooficial.hpg.com.br/plano_nac_ educacao.htm>. Acesso em 22 marr.2017.

EYNG, A. M. Planejamento e gestão do projeto político pedagógico desenvolvendo competências. In: EYNG, A. M. (org.). Planejamento e gestão educacional numa perspectiva sistêmica. Curitiba: Champagnat, 2002. 
FERREIRA, N.S.C. Gestão democrática da educação: ressignificando conceitos e possibilidades. In. FERREIRA, N. S. C.; AGUIAR, M. A. da S. (orgs.). Gestão da educação: impasses, perspectivas e compromissos. São Paulo: Cortez, 2006.

LIBÂNEO, JOSÉ CARLOS. Organização e Gestão da Escola: Teoria e Prática. Ed. 5. Goiânia: Alternativa, 2004.

Cortez, 2005.

JOSÉ CARLOS. Educação escolar, políticas, estruturas e organizações. 2 ed. SP: Cortez, 2011.

JOSÉ CARLOS. Educação escolar, políticas, estruturas e organizações. 10ª ed. SP:

LUCK, HELOÍSA. et al. A escola participativa: o trabalho do gestor escolar. 5. ed. Petrópolis: Vozes, 2005.

H. Concepções e processos democráticos de gestão educacional. Petrópolis: Vozes, 2006. . (Série Cadernos de Gestão)

2009

H. Dimensões de gestão escolar e suas competências.-- Curitiba: Editora Positivo,

LUCKESI, CARLOS CIPRIANO. Gestão Democrática da escola, ética e sala de aula. ABC Educatio, n. 64. São Paulo: Criarp, 2007.

MENEZES-FILHO, N. Educação e desigualdade. In: MENEZES-FILHO, N. A.; LISBOA, M. (Eds.). Microeconomia e sociedade. Rio de Janeiro: Contracapa, 2001.

PARO,VITOR HENRIQUE .Gestão Democrática da Escola Pública. $3^{\text {a }}$ ed. São: Editora Ática,2005.

Cortez, 2008.

VITOR HENRIQUE. Administração escolar: introdução crítica. 15 ed. São Paulo

PEREIRA, S. M.; FERREIRA, L. S. O compromisso dos professores diante da democratização e autonomia na escola: a gestão do pedagógico. Trabalho apresentado no V Congresso Internacional de Educação - Pedagogia (entre) lugares e saberes. São Leopoldo: UNISINOS, 2007.

SANDER, B. Gestão da educação na América Latina: construção e reconstrução do conhecimento. Campinas: Autores Associados, 1995.

SCHNECKENBERG, M. O princípio democrático na atuação do diretor de escola: um estudo comparativo entre diretores eleitos e reeleitos da Rede Pública Municipal de Ensino de Ponta Grossa - PR. Campinas Unicamp, Tese de Doutorado, 2005. 
Id on Line Revista Multidisciplinar e de Psicoloqia

Id on Line Multidisciplinary and Psycology Journal

SILVA, R.C. O professor, seus saberes e suas crenças. In: GUARNIERI, M.R. (Org.). Aprendendo a ensinar: o caminho nada suave da docência. 2. ed. Campinas: Autores Associados, 2005.

WITTMAN, LAURO CARLOS. Gestão Democrática. Curitiba, 2007.

\section{Como citar este artigo (Formato ABNT):}

CARVALHO, Tereza P. S. O.; COSTA, Liliany S.; ALEXANDRE, Lucimara A.C. Gestão Democrática na Escola Pública Contemporânea. Id on Line Revista Multidisciplinar e de Psicologia, Julho de 2017, vol.11, n.36, p.385-406. ISSN: 1981-1179.

Recebido: 27.07.2017

Aceito: 27.07 .2017 